\title{
Transfer of computer-aided diagnosis of dyspepsia from one geographical area to another
}

\author{
JANE C. HORROCKS, DIANNE E. LAMBERT, W. A. F. MCADAM, ${ }^{1}$ A. G. MORGAN \\ C. PACSOO, A. DARNBOROUGH, AND F. T. DE DOMBAL
}

From Airedale General Hospital, Keighley, and The University of Leeds

SUMMARY This paper reports a comparison in Airedale District General Hospital between computer-aided diagnosis of dyspepsia and endoscopy in a prospective unselected series of 165 patients. Patients were interviewed immediately before endoscopy and the findings analysed by a small desk-top computer-aided system. Each 'new' patient was compared by the computer with a group of 360 similar patients from Leeds ( 25 miles away). Overall, $83 \%$ of the positive lesions found at endoscopy were correctly predicted by the computer, including all but three of the 22 cases of gastric cancer. It is suggested (1) that there is little loss of accuracy in transferring the computer-aided system from one locality to another; and (2) that a computer-aided analysis of the patient interview may be of value in selecting 'high-risk' patients for intensive investigation.

We have previously reported the results of computeraided diagnosis of dyspepsia in a series of over 400 cases; and have shown that, using clinical data available at the time of a patient's admission to hospital, a computer-aided system discriminated between the common 'organic' causes of dyspepsia with an overall accuracy of $87.7 \%$ (Horrocks and de Dombal, 1975a). Moreover, we have also shown that at the time of first outpatient attendance, using data elicited at interview by a non-medicallyqualified 'physician's assistant', the same discrimination can be made by the computer with an accuracy of $81 \%$ (Horrocks and de Dombal, 1975b).

Many questions, however, remain unanswered by these previous studies. In particular, perhaps the hardest obstacle of all to overcome in respect of computer-aided diagnosis is this: almost all systems which work quite well in their place of origin have proved considerably less effective in other localities. Could therefore, results equivalent to those in Leeds be obtained in a different (and more rural) location?

In an attempt to answer this question, the computer-aided system used in Leeds in previous experiments was 'transferred' to a District General Hospital some 25 miles from Leeds, and a series of 165 patients coming to endoscopy were interviewed

${ }^{1}$ Address for reprint requests: Mr W. A. F. McAdam, Airedale General Hospital, Steeton, Keighley BD20 6TD, Yorkshire, England.

Received for publication 8 June 1976 and analysed. The present report (1) compares the results of computer-aided diagnostic prediction in Leeds and Airedale; (2) compares the results of the computer-aided analysis with the findings on endoscopy; and (3) assesses the prospects for using a small system of this kind to 'screen' dyspepsia patients for cancer.

\section{Methods}

\section{DEFINITION OF DYSPEPSIA}

As we have previously pointed out the term 'dyspepsia' is exceedingly vague and needs amplification. For the purposes of the present investigation, scrutiny was limited to patients presenting with abdominal, usually upper abdominal, or retrosternal pain (including cases of mild 'discomfort') and/or symptoms referable to the upper gastrointestinal tract such as nausea, vomiting, loss of appetite, or jaundice.

The study was limited to adult patients and excluded patients coming to endoscopy solely for haematemesis.

\section{CLINICAL MATERIAL}

We studied two groups of patients. Initially, we studied a prospective group of 104 patients presenting to a combined medico/surgical 'endoscopy' clinic run by two of us (W.A.F.M. and A.G.M.) at the Airedale General Hospital, Yorkshire, between 
January 1974 and January 1975 . The series, although not in practice consecutive, because of illness and holiday periods, was unselected. In the 'second phase' of our survey we studied 61 similar patients presenting between January 1975 and July 1975, making an overall total of 165 cases.

\section{CONDUCT OF STUDY}

Each patient normally spent one day in hospital. Before endoscopy (in addition to a routine assessment concerning the patient's fitness for endoscopy) the patient was asked to consent to a detailed interview by one of us (J.C.H. or D.L.-in each case a non-medically-qualified physician's assistant) concerning the presence or absence of the symptoms listed in Table 1. After premedication, endoscopy was then carried out. Each endoscopy was performed under premedication of $50 \mathrm{mg}$ pethidine and $0.6 \mathrm{mg}$ atropine. The patients gargled immediately before endoscopy with $2 \%$ amethocaine after which 4-30 $\mathrm{mg}$ diazepam (Valium) was administered intravenously, the dose being judged by the reaction of each individual patient. The instrument of choice for performing endoscopy was an Olympus GIF/D, though occasionally, where this would not be tolerated, an Olympus JFB was used. The findings on endoscopy were recorded 'blind' in the sense that details of the computer analysis of the pre-endoscopy interview were withheld until both endoscopists had noted their findings, and subsequently, results of the two forms of analysis were compared.

\section{COMPUTING SYSTEM USED}

The computing system was identical with that used in our earlier study (q.v.) and was built around a WANG 700 desk-top computer. This system has already been described and costed in detail (Horrocks 1974)

RADIOLOGICAL FINDINGS

The barium studies performed during this trial

Table 1 Attributes sought from patients at each interview

\begin{tabular}{ll}
\hline Age & Nausea \\
Sex & Vomiting \\
Site of pain at onset & Haematemesis \\
Site of pain at present & Appetite \\
Radiation & Dysphagia \\
Duration & Previous indigestion \\
Pattern of pain & Jaundice \\
Severity & Bowels \\
Progress & Micturition \\
Aggravating factors & Weight \\
Relieving factors & Previous abdominal surgery \\
Pain relation to meals & Drugs \\
Night pains & \\
Family history & \\
Smoking habit & \\
Alcohol & \\
Time off work & \\
\hline
\end{tabular}

consisted of conventional barium meal examinations using Micropaque (A.D.) and a modified double contrast method (C.P.) which made use of Baritop and Baritop Gas tablets. No paralysing drugs were used and the area gastricae have not routinely been seen. At present trials are taking place to assess the feasibility of doing all barium meal examinations using the full double contrast technique.

DATA ANALYSIS

Before the analysis which forms the basis of the present trial, the computer was provided with a data base of clinical information from a series of $\mathbf{3 6 0}$ similar patients meticulously collected over a period of approximately one year in Leeds. The information categories noted for each patient are indicated in Table 1 from which it will be seen that the inquiry concentrated upon interview data, physical findings being excluded from the present study. As before, the method of analysis used a variant of Bayes theorem, upon which we have already commented in some detail (Horrocks and de Dombal, 1975a). It will, therefore, be seen that we have attempted to analyse patients using a data base collected in a different geographical (and socioeconomic) environment, posing a severe test of the 'robustness' of the data previously collected in Leeds.

\section{Results}

FIRST PHASE: ENDOSCOPIC FINDINGS

The findings on endoscopy are listed in Table 2 for each of the 104 patients initially studied. In a substantial proportion of the cases $(51.9 \%)$ the endoscopy was said to be negative in the sense that no abnormal findings were recorded. The proportion of patients with peptic ulceration was roughly equally divided between patients with duodenal and gastric ulceration, while 13 of the 104 patients were found to have gastric cancer on endoscopy (and subsequent analysis of biopsy specimens thus obtained).

COMPARISON BETWEEN COMPUTER-AIDED PREDICTION AND ENDOSCOPY FINDINGS This analysis is shown in detail in Table 3. As will

Table 2 Endoscopic findings in 104 cases in first phase of study

\begin{tabular}{llc}
\hline & Cases & \\
\cline { 2 - 3 } & $($ No. $)$ & $(\%)$ \\
\hline Normal & 54 & $51 \cdot 9$ \\
Gastric cancer & 13 & $12 \cdot 5$ \\
Duodenal ulcer & 17 & $16 \cdot 3$ \\
Gastric ulcer & 16 & $15 \cdot 4$ \\
Pyloric ulcer & 4 & $3 \cdot 8$ \\
\hline
\end{tabular}


be seen, a computer-aided prediction of organic disease was usually paralleled by comparable findings on subsequent endoscopy. Only four patients with positive endoscopic findings were predicted by the computer-aided system to be suffering from 'functional' dyspepsia, and of the 13 patients found (after histopathological examination of a series of biopsy specimens) to have gastric cancer, 11 were correctly predicted by the computer analysis. In all, in respect of the patients with 'positive' endoscopic findings, the computer-aided prediction matched these findings in $84 \%$ of the patients.

The same, however, cannot be said of the patients with no apparent abnormality on endoscopy. In just over one-third of these patients the computer-aided system predicted that the endoscopy findings would be positive. Interestingly, a proportion of them (11 out of the 54 patients, $20.4 \%$ ) had shown positive evidence of disease in the past. Usually this was radiological evidence of duodenal ulceration and was matched in seven cases by a computer-aided prediction of peptic ulceration. Whether endoscopic findings or computer-aided prediction are more 'reliable' in terms of prognosis in these cases is a matter which can only be answered by further study (vide infra).

Table 3 Detailed findings in first phase of studycomparison of computer-aided prediction and endoscopic findings

\begin{tabular}{llcc}
\hline $\begin{array}{l}\text { Endoscopy } \\
\text { findings }\end{array}$ & \multicolumn{2}{l}{ Computer prediction } \\
\cline { 2 - 4 } & Normal & Ulcer & Cancer \\
\hline Normal & 34 & 12 & 8 \\
Ulcer & 4 & 31 & 2 \\
Cancer & - & 2 & 11 \\
\hline
\end{tabular}

Table 4 Comparison between two 'phases' of study in which patients were interviewed (phase 1) by one of instigators of system (J.C.H.) and (phase 2) by a previously untrained non-medically-qualified 'physician's assistant' (D.L.)

\begin{tabular}{llll}
\hline & $\begin{array}{l}\text { Phase 1 } \\
\text { (104 patients) }\end{array}$ & $\begin{array}{l}\text { Phase 2 } \\
(61 \text { patients) }\end{array}$ & $\begin{array}{l}\text { Whole study } \\
\text { (165 patients) }\end{array}$ \\
\hline $\begin{array}{l}\text { No. of patients with } \\
\text { endoscopic lesions }\end{array}$ & 50 & 31 & 81 \\
$\begin{array}{l}\text { Computer prediction } \\
\text { Correct }\end{array}$ & 42 & 25 & 67 \\
$\begin{array}{l}\text { Incorrect } \\
\text { Accuracy (\%) }\end{array}$ & 8 & 6 & 14 \\
$\begin{array}{l}\text { No. of cancers seen } \\
\text { endoscopically }\end{array}$ & 13 & 81 & 83 \\
$\begin{array}{l}\text { No. predicted correctly by } \\
\text { computer-aided system }\end{array}$ & 11 & 9 & 22 \\
\hline
\end{tabular}

SECOND PHASE: OVERALL FINDINGS

In the second 'phase' of the study, the computeraided system was run (and the patients interviewed) by one of us (D.L.) who had no previous knowledge of, or familiarity with, 'dyspepsia' and who was not medically qualified. In this phase an additional 61 patients were studied. The results showed that the system's overall detection rate for patients with positive endoscopic findings was only slightly changed $(81 \%$ vs $84 \%)$ and the detection rate for gastric cancer (eight out of nine cases) actually rose marginally during this latter phase. These results are encouraging, for they indicate that the system works equally well when handed over by its instigators (J.C.H. and F.T.deD.) to a different operator (D.L.) in a different geographical area.

\section{CANCER DETECTION}

It is noteworthy that 19 of the 22 cancer cases were diagnosed by the computer-aided system on the interview findings alone. Of course, some of these cases were referred with a firm diagnosis of gastric cancer to the endoscopy clinic merely for histological confirmation. In almust half the cases, however, the initial radiological findings were either dubious or negative. (This is discussed in more detail later).

If one then asks the question 'How well does the computer predict cancer?' an interesting picture emerges. The computer-aided system predicted cancer in some 36 patients and 19 of these 36 patients were shown actually to have cancer on endoscopy. Of the 129 patients predicted not to have cancer by the computer-aided system, only three proved to have cancer on endoscopy. (One patient had cancer of the oesophagus and one had carcinoma-in-situ in a pre-existing gastric ulcer).

\section{' $X$-RAY NEGATIVE' DYSPEPSIA}

In addition, a series of 12 patients was referred direct to the endoscopy clinic because, despite negative radiological findings, the radiologist (A.D. or C.P.) felt there was a possibility that organic disease might be present. Three patients out of the 12 did in fact have organic lesions and all of these lesions were correctly predicted by the computer analysis. Of the remaining nine patients in whom no lesion was seen at endoscopy seven were predicted to have functional disease by the computer.

FURTHER FOLLOW-UP

In comparing any form of diagnosis with endoscopy findings, it is always desirable to avoid the impression that the findings on endoscopy constitute the 'final' diagnosis. This particularly applies to the patients with 'negative' endoscopic findings and an effort was made therefore to find out what happened to 
these patients during the ensuing year after their negative endoscopy.

Six of the patients with initially 'negative' endoscopic findings had developed further evidence of peptic ulceration during the year. Four of these patients were predicted to have peptic ulcer by the computer-aided system, and two were predicted to have 'functional' dyspepsia at the time of the original assessment. One patient, predicted by the computer-aided system to have gastric cancer, but found on endoscopy to have a linear peptic ulcer, was shown at laparotomy six months later to be suffering from cancer of the transverse colon. One other patient (predicted by analysis of his symptoms to have gastric cancer after an initially negative endoscopy) died from carcinomatosis throughout the abdomen, although the primary source was not thought to be within the gastrointestinal tract.

In retrospect, therefore, the findings on one-yearly review do not change our overall conclusions. When amendments of diagnosis with the advantage of hindsight are taken into account, the accuracy of the computer-aided system rises slightly to around $85 \%$ but this change is minimal.

\section{Discussion}

The purposes of this study have already been outlined. As regards the first of these-namely, to determine whether a system devised in our own area would work in a different geographical locationthe answer must be cautiously optimistic. The overall accuracy of the system in Leeds was between $80 \%$ and $90 \%$ and, when transported to a different location, the accuracy in respect of organic conditions remained reasonably comparable at $83 \%$.

In this connection it is worth pointing out that the Airedale District General Hospital (although less than 30 miles from Leeds) draws patients from a totally different population. Most Leeds patients live in a large metropolitan area around the hospital; whereas Airedale General Hospital serves a number of small 'mill' towns (such as Keighley) and also the large rural area of the Yorkshire Dales.

There is one proviso which must be addednamely, that the Leeds and Airedale series were not strictly comparable. The Leeds series dealt with patients coming to operation (and also included a few such patients with biliary trouble) and in the Airedale series a different group of patients were studied-namely, those coming to endoscopy. Nevertheless, the 'reliability' of endoscopy (especially in relation to positive findings) is fairly high and in the short-term follow-up of these patients we have not had cause to change our views. We think it a reasonable conclusion on the present data to state that the system as originally tested in Leeds is fairly 'robust'.

Particularly encouraging is the finding that the accuracy of the computer-aided system remained relatively high, even though the data in this study were elicited from patients by two non-medicallyqualified physician's assistants, one of whom (D.L.) was totally unfamiliar with dyspepsia before the beginning of the study.

As regards the future role of a computer-aided predictive system, though no definitive conclusion can be reached, certain possibilities can be suggested. For example, in the present series of 165 patients, a relatively small group (36) were predicted by the computer to have cancer; and of this group of patients, 19 actually did have the disease. It would therefore seem reasonable to suggest that a computer aided predictive system may be of some value in areas where endoscopy is not routinely available, in order that patients at 'high-risk' from gastric cancer might be referred at once for intensive investigation.

In Airedale, liaison between radiologists and endoscopists is such that patients with any suspicion of neoplasia on radiological investigation were referred promptly for endoscopy. This may to some extent have biased the results 'against' the radiologist, in that the radiologist may have felt more inclined to word a report cautiously knowing that the patient was referred for prompt endoscopy. It is certainly worth pointing out that the patients with 'dubious' radiological findings were referred promptly for intensive investigation rather than sent away for their cancer to 'declare itself'.

Nevertheless, in other centres where such liaison does not exist, there is frequently considerable delay in the establishment of a firm diagnosis of gastric cancer. The procedures suggested as a result of the present trial closely correspond with the suggestions of Cox and his colleagues (Segal et al., 1975)namely, that there should be much more integration between the various diagnostic modes. In this instance, we propose that patients presenting with dyspepsia should be screened by a careful interview and a detailed analysis made of the data. Analysis is currently based around a small desk-top computer, but we are attempting to develop a more simple non-computer-based 'scoring' system. High risk patients may then be referred for intensive investigation such as double-contrast barium studies and/or endoscopy.

Quite clearly, however, despite initial encouraging findings, such assertions and systems need to be put to further tests; and in particular it will be inter esting to see if general practitioners can use this type of system to identify 'high-risk' patients before hospital 
referral. We plan to undertake such studies in the immediate future.

One of us (J.C.H.) was aided by a grant from the Medical Research Council, which we acknowledge with gratitude. In addition, D.L. was aided by a research grant from the Department of Health and Social Security, which we also gratefully acknowledge. Finally, and particularly, we are grateful to the patients for consenting to an additional interview and giving us both their time and helpful advice.
References

Horrocks, J. C. (1974). A computer-aided diagnostic system using a small desk-top computer-calculator. Methods of Information in Medicine, 13, 83-88.

Horrocks, J. C., and de Dombal, F. T. (1975a). Computeraided diagnosis of dyspepsia. American Journal of Digestive Diseases, 20, 397-406.

Horrocks, J. C., and de Dombal, F. T. (1975b). Diagnosis of dyspepsia from data collected by a Physician's Assistant. British Medical Journal, 3, 421-425.

Segal, A. W., Healy, M. J. R., Cox, A. G., Williams, I., Slavin G., Smithies, A., and Levi, A. J. (1975). Diagnosis of gastric cancer. British Medical Journal, 2, 669-672. 